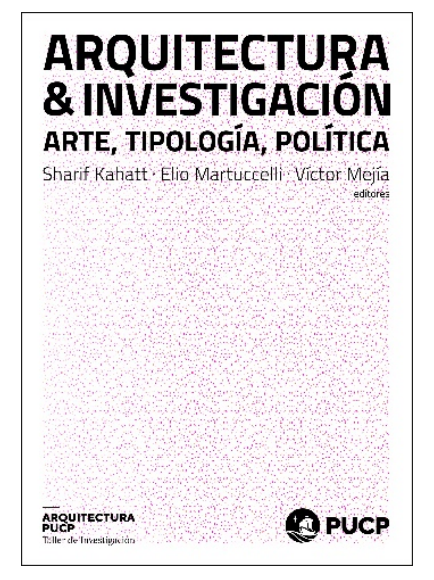

Arquitectura \& Investigación

Arte, tipología, política

ISBN 978-612-47555-5-2

Patrimonio ignoto y registro ausente. Presente de tres estaciones del Ferrocarril Central del Perú: Vitarte, Monserrate y Patio Central-Callao

Daniel Hernández Ramos

Para citar este artículo: Hernández R., D. (2021). Patrimonio ignoto y registro ausente. Presente de tres estaciones del Ferrocarril Central del Perú: Vitarte, Monserrate y Patio Central-Callao. En S. Kahatt, E. Martuccelli y V. Mejía (Eds.), Arquitectura \& Investigación. Arte, tipología, política (p. 123.137).

Pontificia Universidad Católica del Perú.

DOI: $\underline{10.18800 / 978-612-47555-5-2.006}$

Para acceder a este artículo: https://doi.org/10.18800/978-612-47555-5-2.006

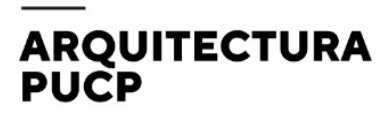



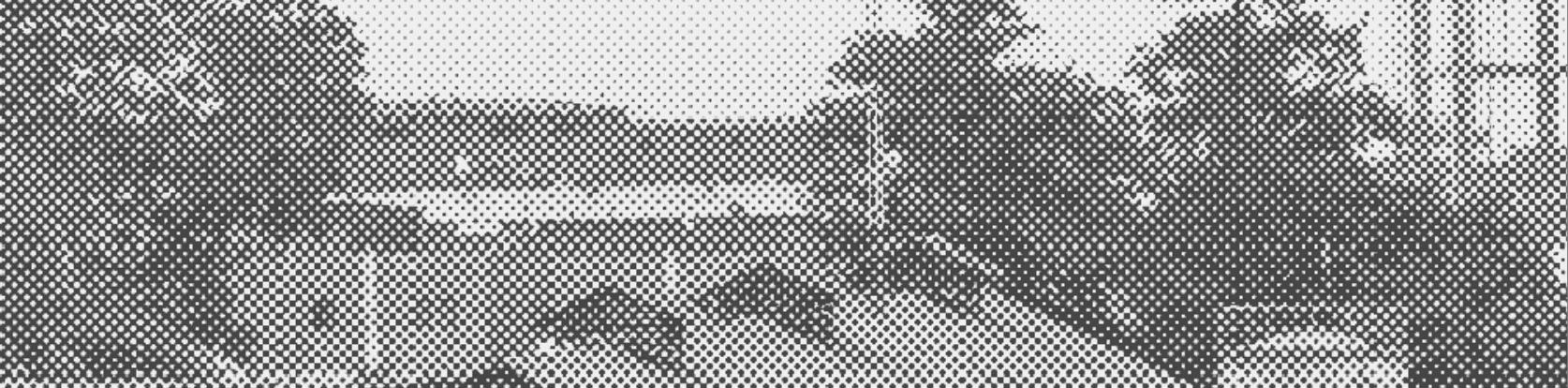

II

,

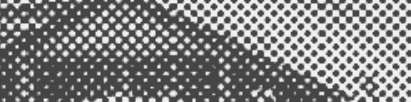

济

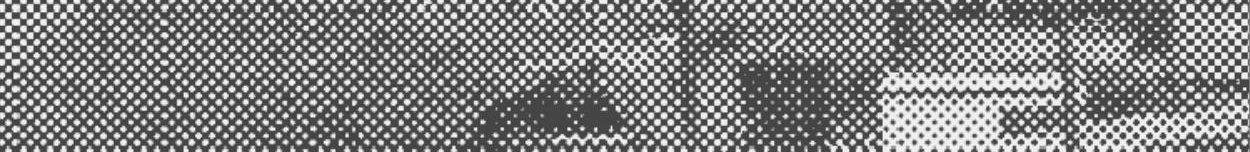

or
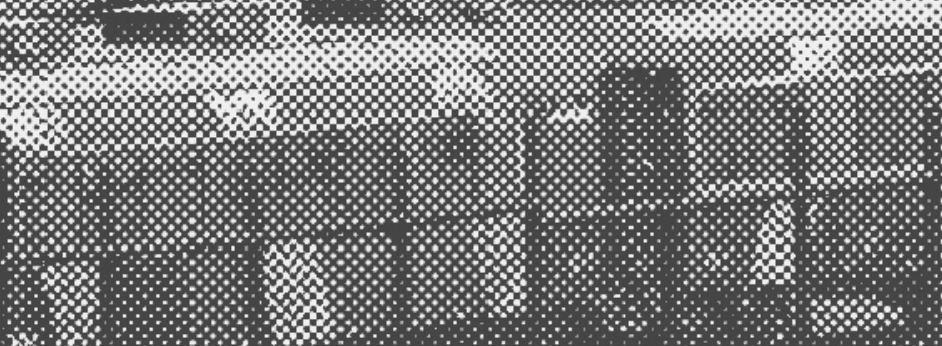

\%
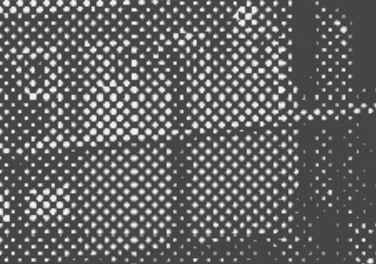

$x$
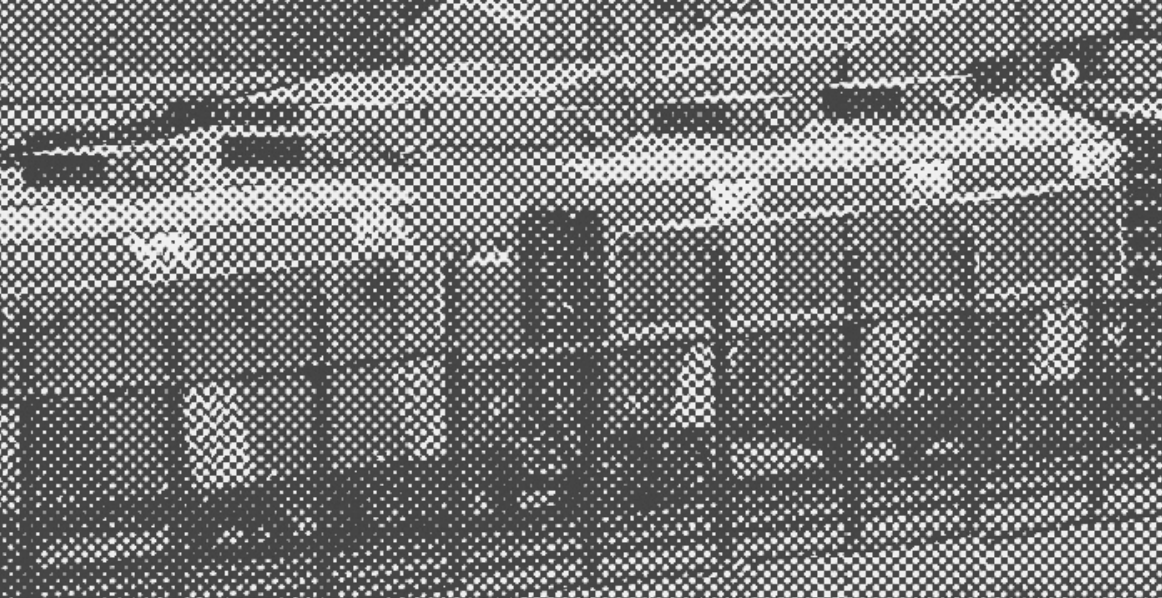


\title{
PATRIMONIO IGNOTOY REGISTRO AUSENTE Presente de tres estaciones del Ferrocarril Central del Perú: Vitarte, Monserrate y Patio Central-Callao
}

\author{
Daniel Hernández Ramos
}

\begin{abstract}
Resumen
El acervo cultural del Perú contempla un variado registro de bienes inmuebles acumulado en las distintas etapas de desarrollo del país. Un amplio grupo de estos exponentes, denominado patrimonio industrial, se halla en un franco estado de deterioro debido al desconocimiento de su relevancia. Algunos edificios representativos de este conjunto son las estaciones del Ferrocarril Central del Perú, todavía vigentes en uso e integridad. El estudio se articula alrededor de la evaluación del estado actual de estos edificios en su dimensión arquitectónica y, complementariamente, en la revisión de las relaciones con su contexto urbano inmediato. Se han seleccionado las estaciones del Callao, Vitarte y Monserrate, por su envergadura arquitectónica e importancia para la ciudad. El análisis de estos inmuebles se lleva a cabo a través de la revisión de documentos técnicos actuales, la comparación histórica y el estudio de la realidad física de cada edificio.
\end{abstract}

Palabras clave: patrimonio industrial, estaciones de ferrocarril, conservación de monumentos, deterioro, arquitectura.

\section{Abstract}

The cultural heritage of Peru contemplates a diverse collection of buildings accumulated throughout the history of the country. A large set of these elements, denominated as industrial heritage, are endangered and deteriorated due to the lack of knowledge of their significance. Some of the most important buildings of this heritage are the stations of the Peruvian Central Railway, still in good shape and running. This article evaluates the architectural dimension of the stations in their current state, as well as examines its relationship with their immediate urban context. For the purpose of this

Daniel Hernández Ramos Estudiante de la Facultad de Arquitectura y Urbanismo PUCP. Cursó estudios de intercambio en la Facultad de Arquitectura de la IUAV, Universidad de Venecia. Desarrolló el presente artículo durante el ciclo académico 2020-1. research, Callao, Vitarte, and Monserrate stations were selected due to their architectural scale and location relevance in the city. The analysis of these buildings was performed under a revision of current technical documents, a historical comparison, and a study of the physical reality of each building.

Keywords: industrial heritage, railway stations, preservation of monuments, deterioration, architecture. 


\title{
PATRIMONIO IGNOTO Y REGISTRO AUSENTE Presente de tres estaciones del Ferrocarril Central del Perú: Vitarte, Monserrate y Patio Central-Callao
}

\author{
Daniel Hernández Ramos
}

\section{El registro ausente}

¿Cuántos peruanos saben que es posible viajar en tren directamente desde el Callao hasta el Valle del Mantaro desde hace más de cien años? ¿Cuántos conocen que gran parte de la infraestructura original de esta ruta se encuentra vigente? Estas preguntas encuentran lugar en una sociedad que continúa ignorando gran parte de su patrimonio, «un conjunto de bienes que surgieron en torno al desarrollo industrial y que obtuvieron un rango de valor por su uso a través del tiempo». ${ }^{1}$ Wiley Ludeña afirmaba en el año 2008 que el patrimonio industrial no era todavía un tema, discurso institucionalizado ni cultura cotidiana en el Perú (2008: 95). Lamentablemente, doce años después, el panorama de este patrimonio es el mismo. Así pues, el acervo industrial se encuentra todavía ausente en la normativa patrimonial vigente del año 2016, ${ }^{2}$ y es aún más inquietante que no se haya realizado un catastro institucional de estos bienes.

Entre todos los exponentes de este patrimonio, sobresale el Ferrocarril Central del Perú, un proyecto que buscó enlazar Lima con el valle de Jauja, que implicó gestiones de agentes públicos y privados, y que tuvo un extenso desarrollo durante casi cuarenta años. Se comenzó a construir en el año 1870 bajo la política ferroviaria del presidente José Balta y la gestión del empresario Henry Meiggs, financiado por una desmesurada deuda externa. Posteriormente, en 1908, la obra culminó con la extensión de la línea hasta la ciudad de Huancayo y con un panorama completamente distinto, pues la gestión y posesión se habían privatizado. En el escenario actual, el Ferrocarril Central brinda servicios turísticos y de transporte y casi la totalidad de sus instalaciones están a cargo de Ferrovías Central Andina S.

1 Definición de patrimonio industrial peruano elaborada por Neydo Hidalgo (entrevista con el autor, 23 de mayo de 2020).

2 La Ley General del Patrimonio Cultural de la Nación (Ministerio de Cultura 2016) no hace alusión, en ningún sentido, al patrimonio industrial. A., empresa que obtuvo la concesión de la vía en 1999 por un período de cuarenta años. No obstante, los servicios de transporte de mercancías y pasajeros los prestan otras sociedades, como Ferrocarril Central Andino S. A., Impala Terminals e, incluso, el Estado peruano (figura 1).

En otro sentido, el proyecto integral del Ferrocarril Central compuso una red de estaciones de significado y técnica relevantes. Estos edificios cumplieron la función de aproximar directamente al ferrocarril con el ciudadano peruano del siglo XIX; no solo articularon los servicios 


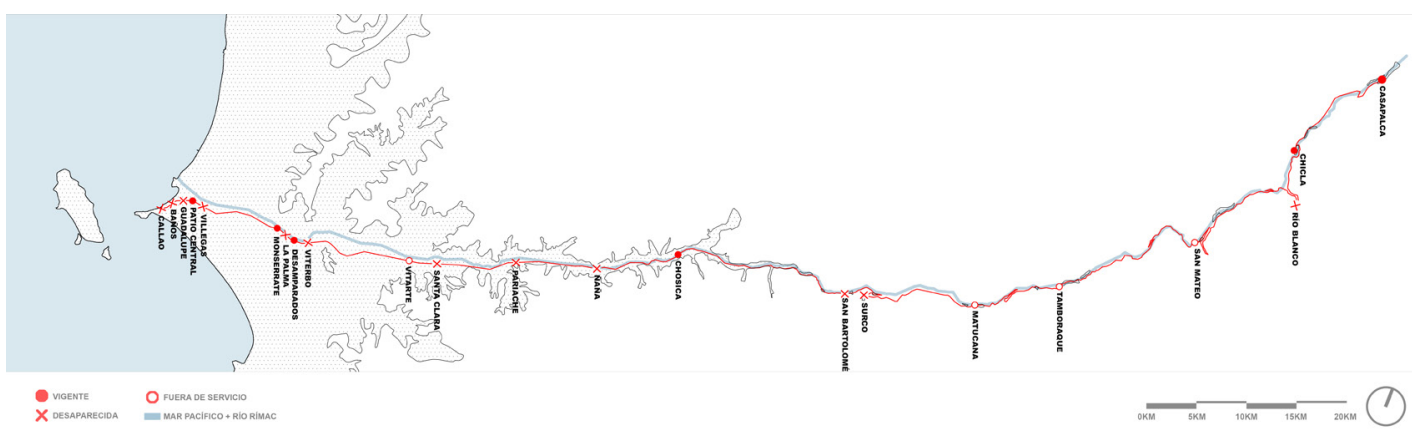

\section{FIGURA 1}

Reconstrucción de la ruta y estado actual de las estaciones del Ferrocarril Central en la región Lima. Elaboración propia. Fuente: Galessio, Costa y Laurent, Contrato de concesión del Ferrocarril Central y base de datos de Google Maps.
3 Inicialmente, el Ferrocarril Central fue de propiedad del Estado peruano; en 1890 fue entregado a la empresa privada Peruvian Corporation; en 1972 se nacionalizó con la constitución de la Empresa Nacional de Ferrocarriles del Perú (Enafer); y en 1999 se concesionó a la compañía Ferrovías Central Andina S. A. de pasajeros, sino también las necesidades del transporte de mercancías. Las estaciones del Ferrocarril Central fueron originalmente veintisiete, agrupadas sobre todo en la región Lima. Estas se organizaron en edificios que pueden considerarse de tres categorías: patios de maniobras, almacenes de mercancías y estaciones de pasajeros con servicios básicos (Costa y Laurent 1908: 155). Los edificios atravesaron, entre otros muchos inconvenientes, diversas sucesiones de propietarios, y nunca pudieron alinearse a una gestión organizada, vinculada a la ciudad o los intereses públicos. ${ }^{3}$ En consecuencia, el sistema de estaciones se ha deteriorado y muchos se encuentran fuera de servicio, en completo estado de deterioro, mientras que otros desaparecieron.

\section{El registro existente}

Previamente se ha establecido que existe una marcada ignorancia del ciudadano y el Estado sobre el patrimonio industrial en el país; sin embargo, la afirmación no implica al medio académico: se ha escrito sobre el patrimonio industrial en el Perú desde diversas perspectivas y disciplinas. En tal sentido, respecto al Ferrocarril Central, destacan dos investigadores: Elio Galessio, quien repasa la historia ferroviaria del Perú mediante el análisis histórico y estadístico de casi la totalidad de rutas de ferrocarriles del país (Galessio 2007); y Klaus Kemp, quien aborda el fracaso de la inversión en la construcción de ferrocarriles a través de las distintas etapas en las que se desenvolvió esta empresa (Kemp 2002).

No obstante, a pesar de haber distintas aproximaciones al tema general del Ferrocarril Central, no hay estudios profesionales desde una perspectiva arquitectónica, y mucho menos sobre sus estaciones; incluso la información arquitectónica sobre estas no se encuentra expuesta con claridad. En este sentido surge, pues, la necesidad de evaluar el estado de estos edificios.

El presente análisis se centra en Lima Metropolitana, donde las estaciones de ferrocarril alcanzaron la cúspide de su desarrollo arquitectónico. Para enriquecer y diversificar el estudio, se han considerado tres ejemplos estructuralmente diversos, por su relación con la ciudad y su propuesta arquitectónica: el Patio Central-Callao, de constante vigencia y marcadas 
transformaciones, una de las edificaciones de mayor carácter industrial, con un valor estratégico de impacto metropolitano; la estación Monserrate, de vigencia simbólica y otrora estación principal del circuito, que representa las intenciones originales del proyecto ferroviario y es un elemento decisivo para la ciudad, pues se emplaza en el límite entre el Centro Histórico y el río Rímac; y, finalmente, la estación Vitarte, de distinta envergadura y uso modificado, que denota una propuesta diversa por su composición y localización en el antiguo Barrio Obrero de Ate Vitarte.

Para establecer los parámetros sobre los cuales se evaluarán estos objetos, se precisarán tres ámbitos que definen las principales características de cada exponente a través de las distintas dimensiones de la arquitectura. El primero es el contextual: en este apartado se evaluará el entorno urbano inmediato, es decir, las distintas relaciones de los edificios con los elementos urbanos más próximos. Luego, bajo la dimensión formal, se analizarán las características fundamentales que definen la dimensión arquitectónica, tales como composición, volumetría y espacialidad. Por último, el ámbito técnico, aspecto en el que se evaluará el sistema constructivo empleado, la materialidad y demás técnicas. Adicionalmente, se acompañará cada objeto de estudio con una observación integral de su historia y estado de funcionamiento, junto con los agentes involucrados. En suma, empleando las distintas dimensiones de análisis, se mostrará la situación completa de cada complejo, para establecer un panorama arquitectónico actual.

\section{Estación Monserrate}

La antigua estación principal del Ferrocarril Central se ubica en el Centro Histórico de Lima, en el barrio de Monserrate, del cual proviene su nombre. Este edificio, por más de cuarenta años el inmueble central de la vía, cedió su rango luego del incendio y ulterior edificación de la nueva y moderna estación Desamparados en 1912. El origen de la estación Monserrate se remonta a los primeros trabajos de construcción del ferrocarril en 1870 y, por tanto, ejemplifica las intenciones originales del proyecto y el entusiasmo de la sociedad de la época por el desarrollo ferroviario. ${ }^{4}$

Actualmente la estación, clasificada como monumento según la Resolución Jefatural 515-1989-INC/J, alberga diversos usos, tales como almacén, punto de control para el transporte de carga y pasajeros, y, eventualmente, usos simbólicos. ${ }^{5}$ En dos planes urbanos vigentes está considerada como edificio de valor monumental y emplazamiento estratégico: el Plan Maestro del Centro Histórico de Lima al 2028 (MML 2019), a pesar de consi-

4 Elio Galessio (2007: 67) y Juan Luis Orrego (2008) concuerdan al referirse a la fastuosidad de las celebraciones inaugurales de este inmueble.

5 En esta estación se recibe cada año el cargamento del «tren papero», iniciativa del Ministerio de Agricultura para promover el comercio de dicho tubérculo. derarlo erróneamente como un edificio abandonado, resalta su valor paisajístico y proyecta su recuperación con fines de uso mixto y turístico, por ser un nodo intermodal territorial de interconexión metropolitana; asimismo, el Plan Metropolitano de Desarrollo Urbano de Lima y Callao 2035 (PLAM 2035, MML 2014) considera el entorno de la estación como un intercambio nodal de primer nivel en el marco del desarrollo de un tren de cercanías.

Respecto al ámbito contextual, la estación siempre ha gozado de una ubicación estratégica para la ciudad. Construida en el barrio tradicional 


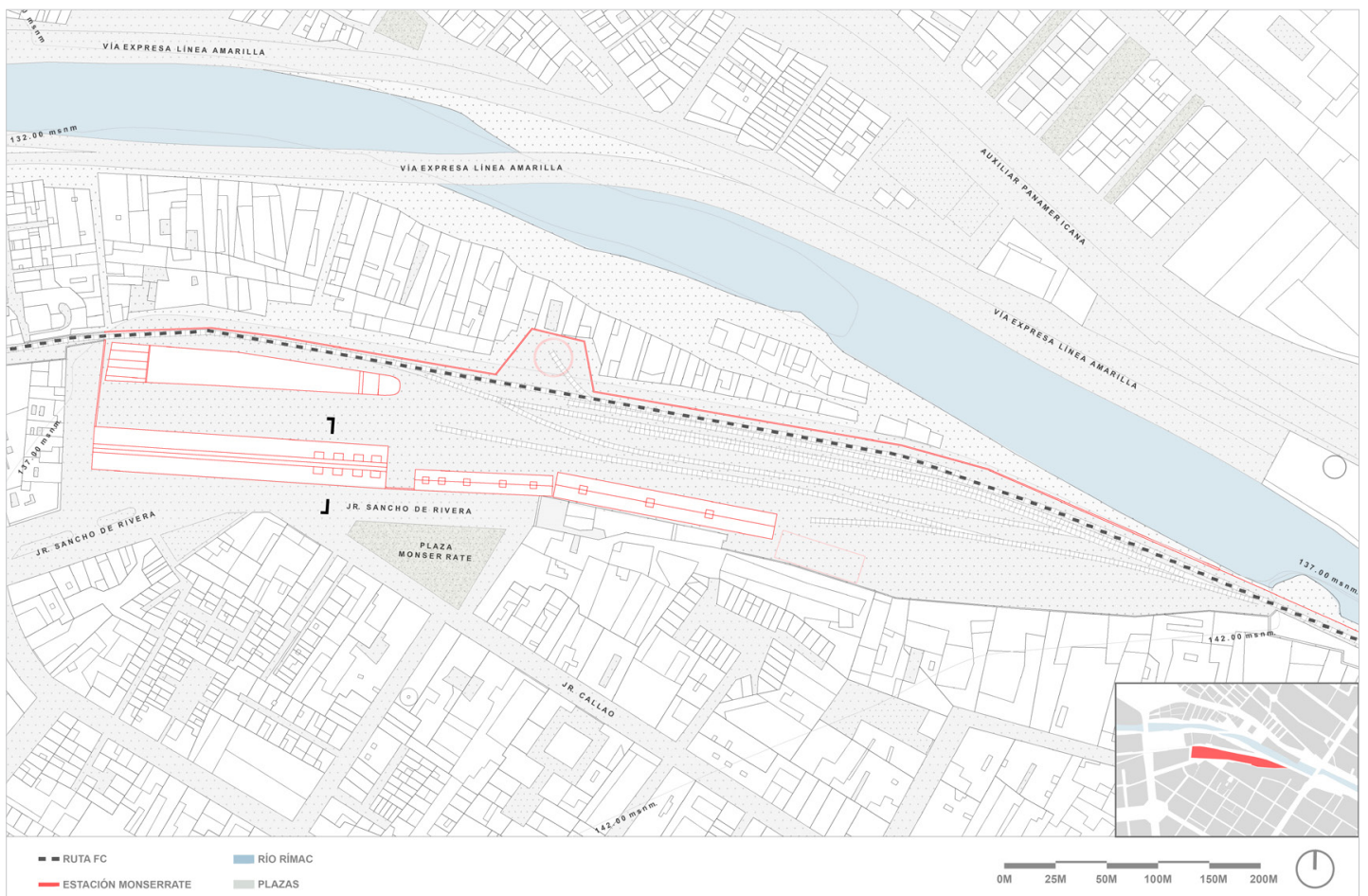

\section{FIGURA 2}

Situación urbana de la estación Monserrate: relación con elementos urbanos y naturales. Elaboración propia, basada en el Archivo Municipal, Ruiz 2018 y fotografías de Google Maps.
6 Sintetizado a partir del diagnóstico realizado por el Plan Maestro del Centro Histórico de Lima 2018-2028. de Monserrate, por el sur colinda con edificios de vivienda y, parcialmente, con la plazoleta del mismo nombre; y por el norte, en desnivel, con el río Rímac. En este espacio, el edificio alentó un nodo comercial de gran importancia a razón de que en el mismo jirón Sancho Rivera, se encontraba el Camal General de Lima: los usos contiguos propiciaron un lugar urbano dinámico, relevante para aquel tiempo (figura 2).

En el contexto actual, el edificio ciertamente no propone las mismas dinámicas urbanas de aquella época. El entorno de la estación, barrio Monserrate, se halla en un estado de deterioro generalizado, derivado de la desarticulación urbana del Centro Histórico y el cambio de uso de suelo. ${ }^{6} \mathrm{~A}$ pesar de ello, el inmueble se encuentra en un ambiente urbano monumental (MML 2019: 134), lo cual denota la importancia histórica del entorno. Finalmente, es preciso mencionar la situación paisajística del inmueble, debido al transcurrir del ferrocarril paralelo al curso del río Rímac. Si bien originalmente la estación tenía una relación física directa con el río, este vínculo está parcialmente interrumpido en la zona noroeste del inmueble. Esto se debe a una primera barrera, producto de la proliferación de viviendas informales, y, desde 2018, una segunda barrera, a razón de la construcción de la Línea Amarilla, parte de una infraestructura vehicular de gran escala.

Sobre los aspectos formales del edificio, el terreno tiene una relación enteramente nula con el exterior por el tratamiento de sus bordes, ya que tanto en los frentes noroeste como suroeste posee un cerco perimetral. En otro sentido, el área construida en el inmueble es tan solo el 15\% del total 
7 El área total del terreno es de 45535 metros cuadrados, y el área construida es únicamente de 7036, según los registros de la Municipalidad de Lima Metropolitana del año 1996, que no han variado desde entonces.

8 En relación con otras obras públicas contemporáneas, como el Palacio de la Exposición (1871), se puede afirmar que el interés por la arquitectura ferroviaria no era comparable al que suscitaban la arquitectura cívica o cultural.

9 En el Callao se encontraban también la maestranza Guadalupe, la estación de La Punta y la Estación Central del Callao, entre muchas otras. del terreno, aproximadamente; ${ }^{7}$ por lo tanto, la estación puede ser confundida con un patio de maniobras. El espacio construido lo componen cuatro volúmenes: tres, usados como almacenes, son vestigios del proyecto original, mientras que el cuarto es un volumen más reciente, para fines de control y servicios actuales. Los tres cuerpos originales son galpones de planta libre a doble altura con cobertura a dos aguas; estos poseen dimensiones de sección y altura distintas, a pesar de su semejanza compositiva. El primero de ellos, ubicado en la esquina suroeste, que puede definirse como el volumen principal, presenta una teatina continua en la cumbrera, vanos altos continuos en los tabiques laterales y teatinas laterales en uno de sus extremos. Actualmente estas aberturas están tapiadas, lo que genera problemas de salubridad, pues resulta un espacio muy amplio sin ventilación. Los otros dos volúmenes son muy semejantes; únicamente varían sus dimensiones. A diferencia del cuerpo principal, consideran teatinas puntuales en la longitud de la cumbrera, lo cual señala que su uso original estaba dividido en ambientes más pequeños (figura 3).

En consideración a la técnica, se puede sostener que la propuesta desarrolla un diseño simple, para fines prácticos, sin mayores aspiraciones. ${ }^{8}$ En los tres volúmenes originales se propone la misma solución, un planteamiento que surge de la necesidad de un espacio continuo y fácilmente modificable en el interior. Este sistema constructivo se resuelve enteramente con listones de madera que varían de espesor y ancho a razón del elemento que definen. La estructura principal se compone de una secuencia sencilla de columnas y tijerales. Esto permite que el espacio pueda volcarse completamente al exterior a través de la apertura de los tabiques exteriores, constituidos por paneles de listones de madera que funcionan en su mayoría como cerramientos batientes. La cobertura del techo se resuelve con listones de mayor dimensión; estos reposan en viguetas sostenidas a su vez por la estructura principal de tijerales. Para los vanos, tanto en las ventanas altas como en las teatinas, se emplean rejillas de madera con secciones redondas.

La situación actual del inmueble denota un estado de deterioro bastante profundo. Es aún más preocupante la pérdida de elementos originales debido a la sustitución de materiales, lo cual compromete el estado de integridad del edificio. Las coberturas de dos de los volúmenes han sido sustituidas por un material sintético contemporáneo, y únicamente el bloque este conserva la cobertura original de madera. De igual forma, se han reemplazado varios tabiques exteriores por otros de albañilería o con nuevos listones de madera. Este es el contradictorio panorama actual de un edificio que no solo es parte del patrimonio industrial del país, sino que también está considerado oficialmente como monumento (figura 4).

\section{Patio Central-Callao}

A razón de las dinámicas urbanas y económicas que continuamente propicia la provincia del Callao, se construyeron en esta localidad instalaciones ferroviarias de diversa jerarquía. ${ }^{9}$ El proyecto original del Ferrocarril 


\section{FIGURA 3}

Estación Monserrate. Sección del cuerpo principal: solución de la cobertura para la ventilación e iluminación de la estación. Elaboración propia, basada en las fotografías de Ruiz 2018.

\section{FIGURA 4}

Estación Monserrate. Vista desde la Vía Expresa Línea Amarilla. Límite norte de la estación con el río Rímac, maquinaria en funcionamiento y galpón este. Fuente: FCrailfan, Ferrocarril Central del Perú, 2018.
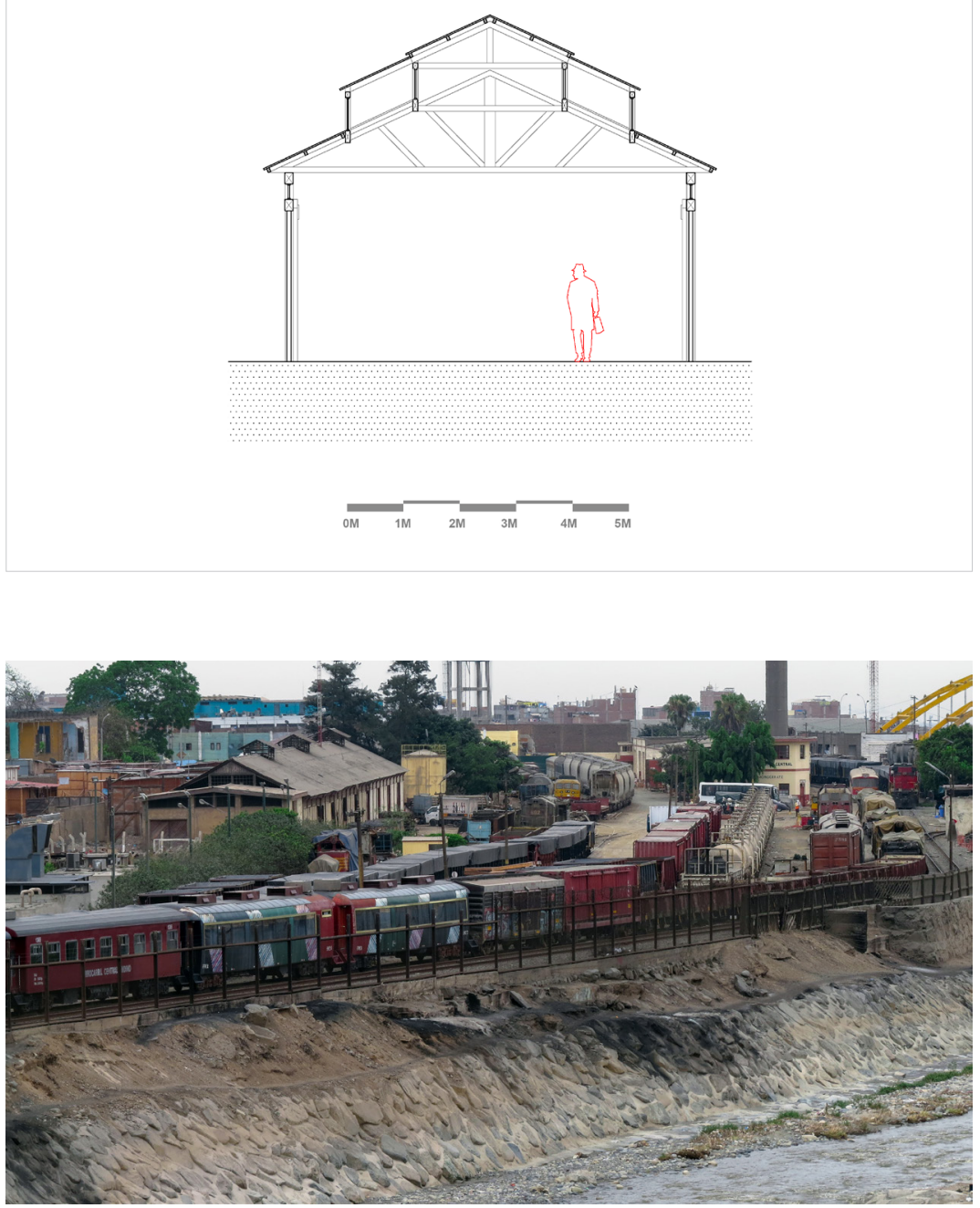
10 Como describe Costa y Laurent, la iniciativa para establecer servicios vinculados al transporte de mercancías en la ruta se concibió desde 1880, cuando Henry Meiggs propuso la perforación del socavón de Rumillana y el asentamiento de un campamento minero (1908: 73)

11 De acuerdo con la zonificación urbana vigente de la Municipalidad Provincial del Callao (2018), el inmueble se encuentra en un entorno de industria elemental.

12 En el marco del programa urbanístico de actuaciones especiales del PLAM 2035 se contempla el «Plan especial de puerto y aeropuerto».

13 Para analizar las áreas del terreno se ha recurrido al metraje consignado en el Contrato de Concesión Ferrocarril del Centro (Agencia de Promoción de la Inversión Privada-República del Perú 1999: 103)

14 Elio Galessio señala, en un plano de reconstrucción de las vías férreas del Callao de 1908, que la vía del ferrocarril incluso accedía directamente a la dársena y muelle del puerto (2007: anexo).
Central propuso un emplazamiento dedicado al transporte de mercancías, un terminal que vinculase los asentamientos mineros del interior con el puerto. ${ }^{10}$ Por orientarse a esta función, el inmueble ha mantenido una vigencia sostenida a lo largo del tiempo, en contraste con otras instalaciones del ferrocarril. Sin embargo, no existe ningún vestigio evidente del edificio construido en la época original, como en el caso de Monserrate, aun cuando este complejo es la única instalación vigente del sistema ferroviario en el Callao. En la actualidad, este terminal posee una relevancia económica importante debido a su relación directa con las instalaciones mineras del valle del Mantaro y su cercanía al puerto del Callao. Por tal motivo, el emplazamiento ha sido cedido bajo un contrato de concesión distinto al del resto de las instalaciones del Ferrocarril Central. Así, en 2001 el Patio Central-Callao fue concesionado por treinta años a Impala Terminals Perú, empresa que brinda servicios de gestión y transporte de concentrados minerales.

En cuanto a las consideraciones urbanas, el conjunto ocupa una gran manzana de íntegra vocación industrial con alto valor estratégico. ${ }^{11}$ El terreno presenta una marcada irregularidad, sobre todo en los extremos este y oeste, debido a la existencia de equipamiento urbano y vivienda, lo que revela la pérdida de integridad urbana del complejo. A propósito de la relación con su contexto más próximo, en dirección noreste colinda con diversas instalaciones derivadas del puerto del Callao, como almacenes y aduanas; en tal sentido, propone un borde disperso, sin elementos que definan su perímetro, por la necesidad de vincularse con dichas instalaciones. En dirección suroeste, el Patio Central representa un borde urbano para la ciudad, pues limita con los conjuntos de vivienda de la provincia y, contradictoriamente, propone un muro perimetral ciego de doble altura en toda esta extensión. Finalmente, en relación con el panorama futuro del inmueble, por su importancia para la ciudad ha demandado un plan urbano específico en el PLAM 2035 (MML 2014), que propone renovar y expandir la zona en la que se halla inmerso (figura 5). ${ }^{12}$

En cuanto a los aspectos formales de la edificación, cabe señalar sus marcadas características industriales. El complejo se articula como un conjunto de volúmenes dispersos alrededor del bloque más antiguo y de mayor dimensión en el centro del terreno. Esta disposición la conforman alrededor de quince galpones independientes de diferente jerarquía, que cumplen las funciones de almacenes, laboratorios de procesamiento y oficinas, entre otras. Ahora bien: bajo el con la instalación de una gran cobertura, se buscó incrementar el área de trabajo en el lote y unificar los usos del complejo. Esta solución define un espacio útil de mayor calidad climática y espacial sobre la cual se puede ejercer un control más ordenado. El gran cerramiento agrupa aproximadamente $80 \%$ del área del complejo, con una solución que se ajusta a las dimensiones del terreno. ${ }^{13} \mathrm{Al}$ margen de la diferencia en el ancho, la cubierta define un espacio de altura continua y características constantes: una vasta extensión de estructuras puntuales con múltiple altura y bóvedas ligeramente traslúcidas. Por último, el Patio Central actualmente no conserva el acceso 


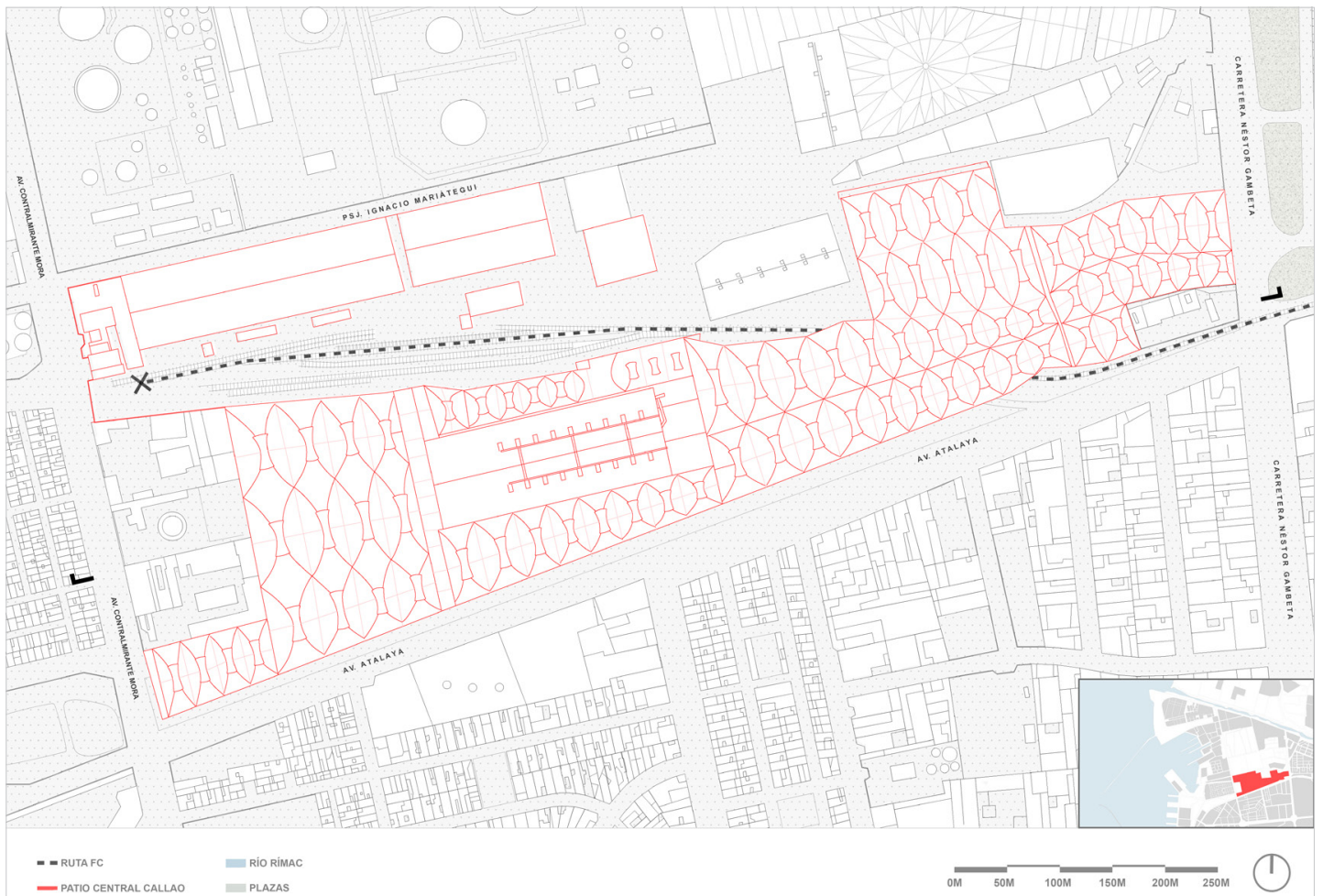

\section{FIGURA 5}

Patio Central-Callao. Situación urbana de la estación, envergadura del complejo y relación con los frentes norte y sur. Colindan con el inmueble los barrios de Ciudadela Chalaca, Gambeta Alta y Barrio Fiscal 1 Elaboración propia, basada en el archivo de Impala Terminals y fotografías de Google Maps.
15 Estas soluciones fabriles no son únicamente propias de la época contemporánea. De acuerdo con el archivo fotográfico de Elio Galessio, la maestranza Guadalupe agrupaba galpones semejantes a los del Patio Central, pero que pertenecían al proyecto original del ferrocarril. ferroviario directo al puerto debido a la clausura de la vía en el límite de la avenida Contraalmirante Mora (figura 6). ${ }^{14}$

En cuanto a la dimensión técnica del edificio, se debe remarcar el uso de soluciones prefabricadas y modulares para responder de manera práctica a las necesidades industriales del conjunto. ${ }^{15}$ Los volúmenes disgregados se articulan a través de tijerales de acero para la estructura y planchas metálicas corrugadas para el cerramiento. Para el soporte de la gran cobertura se emplean columnas de concreto armado establecidas de manera reticular, a las cuales se adosan, en el límite superior, dos láminas de acero; es mediante estos elementos metálicos que los tijerales abovedados transfieren su carga a las columnas. La estructura que desarrolla la cubierta, si bien por sus características podría parecer modular, es más bien una solución orgánica, puesto que muchas retículas responden al movimiento irregular del terreno. Esta gran cobertura se desarrolló progresivamente, en etapas, a lo largo de dos años, y culminó en 2017.

Lógicamente, un edificio, para ser útil, debe adaptarse a las exigencias del usuario en el tiempo o podría replantear sus usos para servir a otras funciones; de lo contrario, en contraste con el presente caso, podría volverse obsoleto, como la estación Monserrate. El estado actual del patio central del Callao define una estación que ha perdido en gran medida su integridad urbana y arquitectónica en relación con la propuesta original del proyecto; sin embargo, se puede afirmar que, debido a esta 


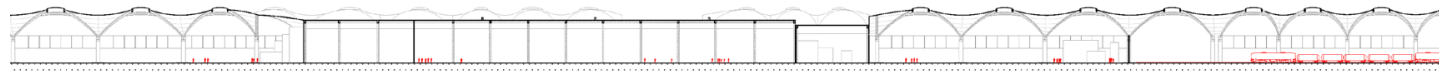

\section{FIGURA 6}

Patio Central-Callao. Sección longitudinal del complejo. Dimensión espacial, espacios de trabajo y almacenes. Elaboración propia. Fuente: archivo de Impala Terminals.

\section{FIGURA 7}

Patio Central-Callao. Vista aérea del complejo. Relación con la vivienda, a la derecha, y con complejos industriales, a la izquierda. Fuente: archivo de Impala Terminals.

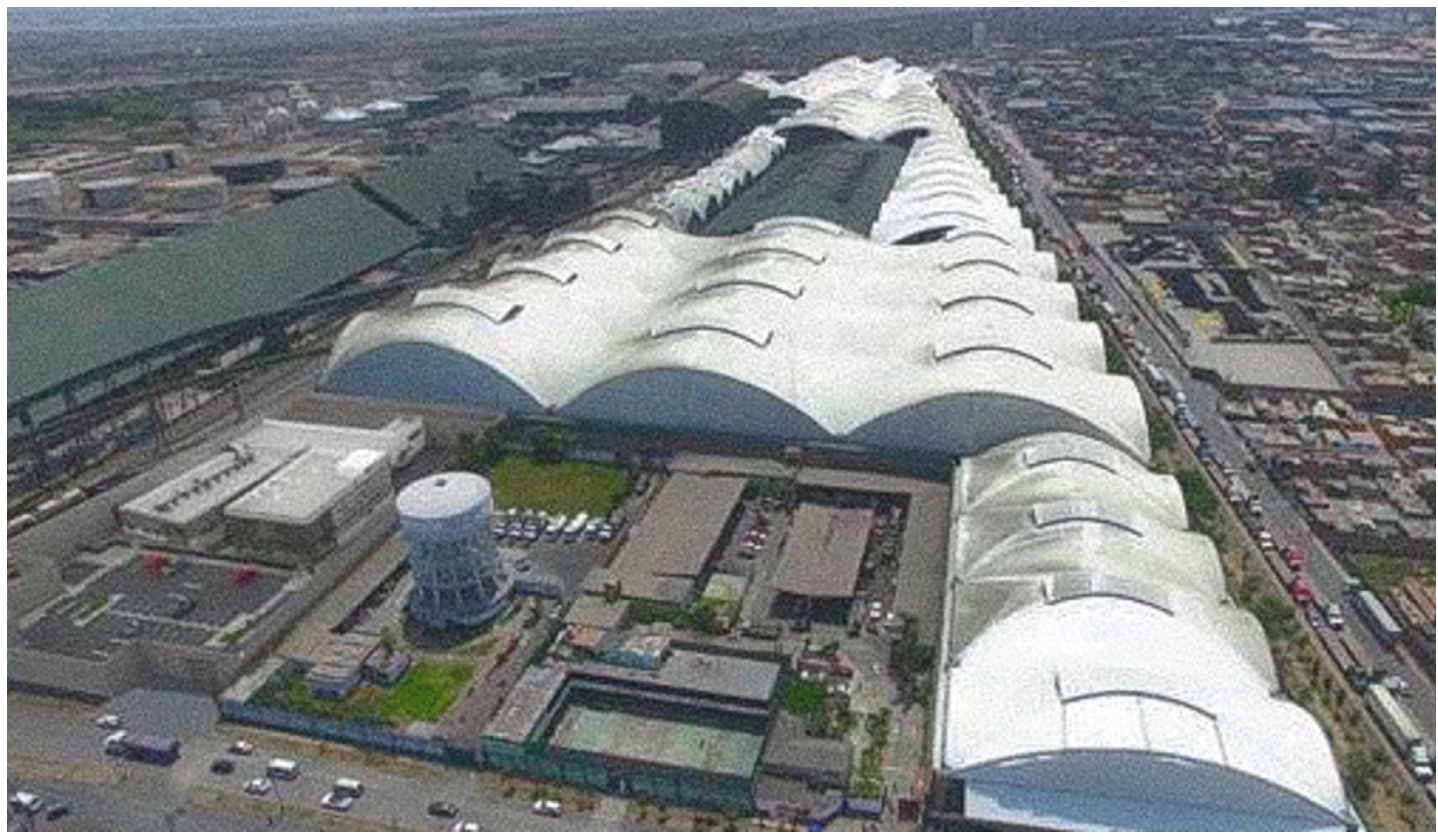


renovación, es el complejo del Ferrocarril Central que se mantiene con mayor vigencia en Lima Metropolitana (figura 7).

\section{Estación Vitarte}

Para abordar este caso se debe comenzar repasando el desarrollo económico y urbano que propició el Ferrocarril Central. ${ }^{16}$ Un año después de la inauguración de la vía, en 1871, se fundó la fábrica textil de Vitarte, ubicada alrededor del kilómetro treinta de la ruta, debido a que se buscaba hacer uso del ferrocarril para transportar las mercancías relacionadas con esta industria. Además, esta empresa propició el establecimiento de una parada del ferrocarril para cubrir sus necesidades tanto comerciales como civiles. De esta manera, de acuerdo con el plan integral del Ferrocarril Central, la estación Vitarte se estableció con la clasificación de paradero, lo cual supone un orden de valor arquitectónico diverso en comparación con otras estaciones; ciertamente, la estación de Vitarte es un edificio de menor envergadura, que albergó usos sencillos. En el escenario actual, el valor del inmueble está relegado sustancialmente al de un edificio simbólico, en el marco del Ferrocarril Central y el significado del Barrio Obrero de Vitarte. Asimismo, ni la propietaria, Ferrovía Central Andina S. A. ni las instituciones públicas de la ciudad, proponen algún tipo de atención para este inmueble; tampoco es aludido en ningún sentido por los planes de desarrollo urbano vigentes, y oficialmente está fuera de servicio (figura 8).

En referencia al contexto, luego de la fundación de la fábrica Vitarte creció el Barrio Obrero del mismo nombre hacia 1898 y, en paralelo al establecimiento de otras industrias textiles en la zona, se reafirmó el tejido urbano de Vitarte. Por su significado social —aquí se gestó el movimiento que propició la aprobación de significativos derechos laborales, entre otras importantes dinámicas sociales-, este entorno, al cual pertenece la estación, fue declarado área histórico-monumental en 1990, lo cual define el valor del edificio más allá de su calidad arquitectónica.

El hecho de ser la estación un elemento precedente en el territorio propició que la vivienda que se fue desarrollando posteriormente se estableciera circundándolo. El conjunto más antiguo, perteneciente al Barrio Obrero de Vitarte, se ubica en dirección oeste de la estación, mientras que las manzanas residenciales establecidas en sentido norte, que suprimieron la relación directa de la estación con el río Rímac, no se desplegaron sino hasta después de 1940. ${ }^{17}$ Ahora bien: todas las etapas de vivienda se cons-

16 Aunque Klaus Kemp sostiene que el proyecto del Ferrocarril Central no generó ningún desarrollo industrial relevante (entrevista con el autor, 4 de junio de 2020), cabe mencionar que hubo algunas excepciones.

17 Esto se constata en un plano del complejo obrero Vitarte realizado en 1941 por A. Quiñones y E. Tola. tituyeron siempre considerando la jerarquía urbana de la estación, la cual se consolidó al ubicar la plaza principal del barrio junto al extremo oeste del inmueble. La cercanía de ambos elementos emblemáticos define una estrecha relación cívica (figura 9).

Sobre su dimensión formal, la condición que define al edificio es la categoría que recibe en el sistema del Ferrocarril Central: su definición de paradero significó, consecuentemente, una propuesta arquitectónica distinta a los anteriores complejos analizados. La estación es, concretamente, un edificio que concentró todos sus servicios en el interior y se estableció 


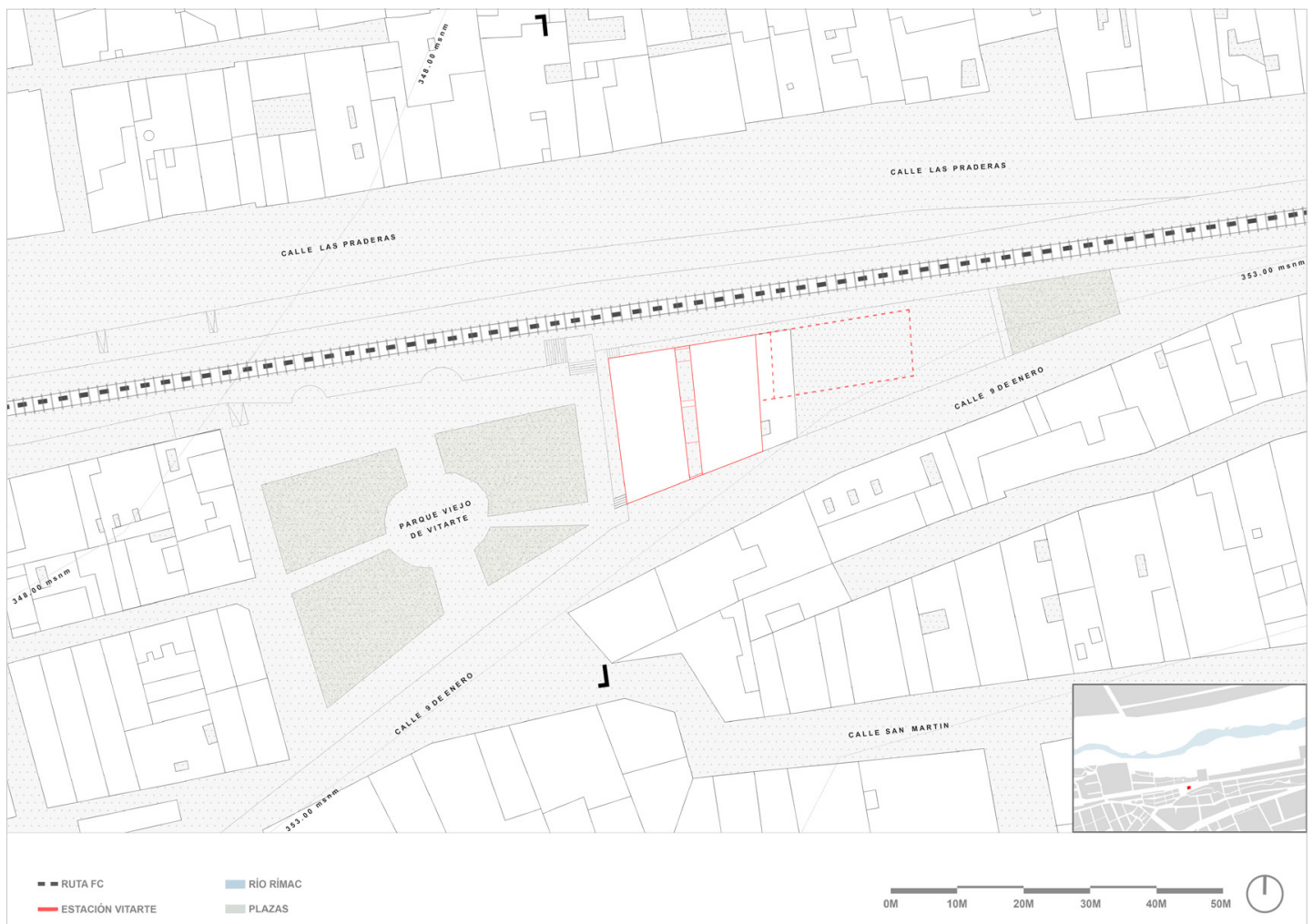

\section{FIGURA 8}

Estación Vitarte. Situación urbana de la estación. Se observa la proyección del volumen destruido y la jerarquía espacial. Elaboración propia basada en el plano de Quiñones y Tola (1941) y fotografías de Google Maps. 


\section{FIGURA 10}

Estación Vitarte. Fachadas noroeste de la estación. Se muestra la relación con el entorno urbano deteriorado y las vías del tren Fuente: Google Street View.

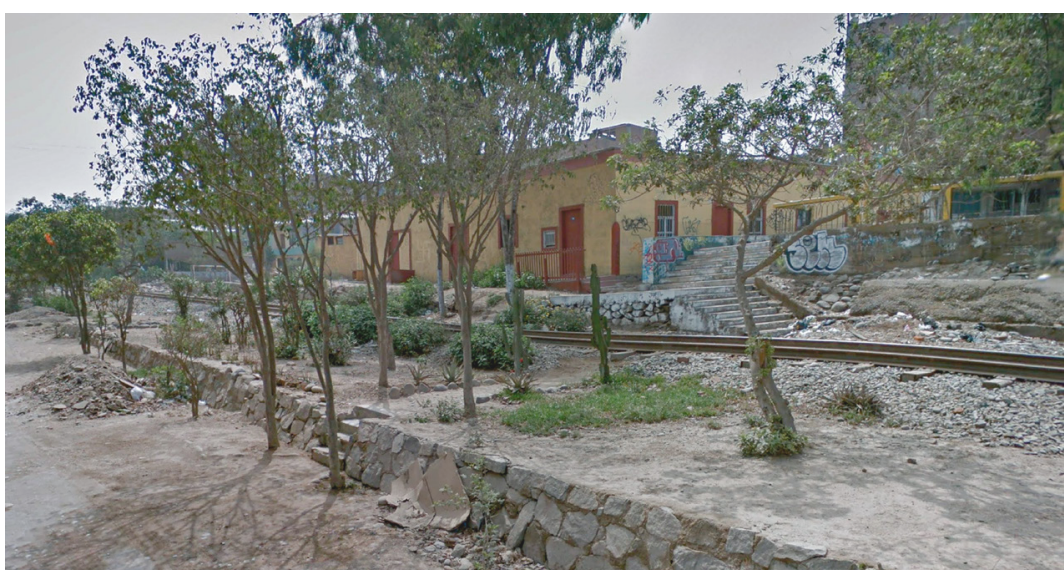

sobre una plataforma elevada del nivel de las vías del tren. En la planimetría del Barrio Obrero de Vitarte realizada en 1941 (Quiñones y Tola) se observa que el inmueble original estaba compuesto por dos volúmenes dispuestos contiguamente. Actualmente solo se conserva el bloque oeste. Se desconocen las causas de la desaparición del otro cuerpo, en cuyo lugar se ha edificado un volumen a lo largo de todo el extremo de la estación. Esta construcción añadida y sus evidentes características de vivienda son señales que permiten asegurar que la Estación Vitarte, a pesar de estar fuera de servicio, está siendo habitada de manera informal. ${ }^{18}$ En otro sentido, el diseño del edificio posee las características propias de una construcción limeña edificada con adobe: se organiza en ambientes reticulares definidos por la variación de una célula de cuatro por cuatro metros, aproximadamente, y posee una losa llana como cobertura.

En el ámbito técnico, la estación Vitarte establece una propuesta sencilla que se orienta más a la arquitectura civil de la época que a una solución industrial. La propuesta estructural del edificio se desarrolló mediante la constitución de muros portantes de adobe y estructura de vigas de madera para el techo. La carpintería de vanos y puertas es de madera y hierro, mientras que el acabado exterior de los muros es en algunas secciones de yeso y en otras de mortero de cemento (figura 10).

Esta condición rudimentaria la ha condenado al abandono y el olvido, y ha relegado su significado al de un hito barrial. No obstante, la estación Vitarte forma parte del grupo de inmuebles perteneciente al Ferrocarril Central; su intención, sus decisiones de diseño y su memoria son parte del proyecto ferroviario nacional y, por lo tanto, pertenece al patrimonio industrial del país, de la misma manera que los complejos del Callao y Monserrate. Aunque parezca una propuesta elemental, definida por sus parámetros técnicos y formales, la estación Vitarte muestra otra dimensión del proyecto ferroviario, con un valor mucho más cotidiano y civil. Así, a través de la exposición de su situación actual se busca señalar también las estaciones restantes de la ruta y las demás instalaciones del sistema ferroviario peruano que se encuentran en el mismo estado de desamparo.
Estación Vitarte. Sección de la estación en su entorno. Se observa la relación con la vivienda circundante y la proximidad a la ribera del río Rímac. Elaboración propia basada en datos de Google Maps.
18 Esta afirmación se sustenta en dos colores de apreciar incluso desde el año 015 a través de una fotografí que revela el cambio de uso del inmueble y la subdivisión de los espacios interiores. 


\section{Conclusiones}

Al abordar el caso de las estaciones del Ferrocarril Central del Perú se ha establecido como primicia el desconocimiento y la falta de información al respecto del tema. Este desinterés se puede sustentar, por ejemplo, en el fracaso del proyecto ferroviario nacional o en la falta de un verdadero movimiento industrial en el país; sin embargo, la legítima causa de la desatención de estos edificios es, sin duda, la falta de información al respecto de sus condiciones e historia. ${ }^{19}$

El estado de las estaciones denota diferentes situaciones según las decisiones de gestión y particulares vicisitudes. El primer caso — un edificio de alto valor histórico, puesto que es uno de los más significativos del sistemapresenta un severo estado de deterioro a pesar de haber sido declarado como monumento histórico, declaratoria que en lugar de haber elevado su valor y garantizado su vigencia, ha relegado a la estación Monserrate a convertirse en un edificio sin uso. Se puede asegurar, en consecuencia, que el camino para la recuperación de estos inmuebles no debe orientarse solamente a una declaración patrimonial desde el Estado, ya que esto es insuficiente para asegurar su adecuada conservación.

El segundo edificio analizado presenta una situación que contrasta con el primero. El Patio Central-Callao ha sufrido severos cambios arquitectónicos y urbanos a través del tiempo, para responder a distintas necesidades. La evolución de los usos y la modificación de la arquitectura se presentan, en este sentido, como solución para resolver el problema de la vigencia de estos inmuebles; no obstante, estos cambios deberían conservar la integridad y autenticidad del complejo. En otro sentido, debido a esta intensa pérdida de integridad, surge la cuestión de si el Patio Central-Callao pertenece o no al patrimonio industrial peruano. La respuesta se halla en el valor histórico de su dimensión urbana: aunque no se conserve ningún vestigio arquitectónico del proyecto original, ciertamente el complejo albergó usos industriales de relevancia histórica; su mérito patrimonial, aunque sesgado, es evidente. ${ }^{20}$

Con el último caso estudiado, la estación Vitarte, se revela el severo

19 Kemp señala que la desventura del proyecto se remonta incluso a su origen: el sustento financiero de la propuesta fue una deuda exorbitante (entrevista con el autor, 4 de junio de 2020). Galessio, por su parte, asegura que la ruina del plan ferroviario nacional se debió a que el sector privado dejo de invertir a causa de la nacionalización de diversas vías (entrevista con el autor, 29 de junio de 2020).

20 El historiador Neydo Hidalgo asegura que el inmueble no tiene valor patrimonial (entrevista con el autor, 23 de mayo de 2020); sin embargo, esto es debatible desde una perspectiva urbana. desconocimiento que existe sobre estos edificios. Esta condición no es, sin embargo, exclusiva de las estaciones del Ferrocarril Central: se repite en muchos otros emplazamientos industriales, lo que provoca el deterioro de estos edificios y su pérdida para la ciudad y el ciudadano. En un sentido, se priva a los peruanos de gran parte de su historia, del testimonio tangible de los procesos políticos y técnicos que desencadenaron los deseos de industrialización del país; y en otro sentido, se le niega a la ciudad el aprovechamiento de emplazamientos que pueden atender ampliamente muchas de las necesidades urbanas que Lima reclama.

\section{Bibliografía citada}

AGENCIA DE PROMOCIÓN DE LA INVERSIÓN PRIVADA-REPÚBLICA DEL PERÚ

1999 Contrato de concesión Ferrocarril del Centro. Lima: Agencia de promoción de la inversión privada. Consulta: 21 de abril del 2020.

https://www.ositran.gob.pe/wp-content/uploads/2017/12/Texto-Actualizado_FVCA.pdf 
COSTA Y LAURENT, Federico

1908 Reseña histórica de los ferrocarriles del Perú. Lima: Lit. y Tipo. Carlos Fabbri.

GALESSIO, Elio

2007 Ferrocarriles del Perú: un viaje a través de su historia. Lima: Aruntani.

KEMP, Klaus

2002 El desarrollo de los ferrocarriles en el Perú. Lima: Universidad Nacional de Ingeniería. Proyecto Historia UNI.

LUDEÑA, Wiley

2008 «Patrimonio industrial en el Perú del siglo XX: ¿exotismo cultural o memoria sin memoria?». Apuntes, vol. 21, n. ${ }^{\circ}$ 1, pp. 92-113, Bogotá. Consulta: 23 de abril de 2020.

https://revistas.javeriana.edu.co/index.php/revApuntesArq/article/view/8968

MINISTERIO DE CULTURA

2016 Ley 28296. Ley general del patrimonio cultural de la Nación. Lima, 3 de diciembre. Consulta: 20 de abril de 2020.

https:/www.cultura.gob.pe/sites/default/files/archivosadjuntos/2016/08/marcolegalokver siondigital.pdf

MML, MUNICIPALIDAD METROPOLITANA DE LIMA

2014 PLAM Lima y Callao 2035: Plan Metropolitano de Desarrollo Urbano. Consulta: 19 de abril de 2020

2019 Plan Maestro del Centro Histórico de Lima al 2028. Consulta: 22 de abril de 2020.

http://www.munlima.gob.pe/plan-maestro-de-recuperacion-del-centro-historico-de-lima

ORREGO, Juan

2008 «La "era del guano": Manuel Pardo y el Partido Civil». En blog.pucp.edu.pe. Consulta: 21 de abril de 2020.

http://blog.pucp.edu.pe/blog/juanluisorrego/2008/08/21/la-era-del-guano-manuel-pardo-yel-partido-civil/

QUIÑONES, A. y E. J. TOLA

1941 Cías. Unidas Vitarte y Victoria S. A. Fábrica Vitarte y Anexos [plano]. Lima: s/e.

RUIZ, Heber

2018 «Estación de tren y centro cultural Monserrate». Tesis para obtener el título profesional de arquitecto. Lima: Universidad Nacional de Ingeniería, Facultad de Arquitectura, Urbanismo y Artes. 